\title{
Once preguntas sobre la relación entre ética y política
}

\section{Eleven Questions on the Relationship between Ethics and Politics}

\author{
Miguel Ángel Polo Santillán ${ }^{1}$ \\ Universidad de Lima \\ Universidad Nacional Mayor de San Marcos
}

\begin{abstract}
RESUMEN
A través de once preguntas, el autor revisa la relación entre la ética y la política. Una idea fuerza del artículo es que el Estado debe su sentido al "bien común", entendido como la protección de la vida y la dignidad humanas. De ese modo, la praxis política debiera ampliarse a la participación de la sociedad civil, para así evitar las debilidades de las instituciones representativas y fortalecer el sentido democrático de las mismas. Mayor participación política de los ciudadanos es darle mayor sentido ético a la acción política, pues se trata de que la gente se haga responsable de sus propias vidas.
\end{abstract}

\section{Palabras clave:}

Ética / Política / Estado / Sentido ético de la política / Democracia /Participación

\begin{abstract}
Through eleven questions, the author reviews the relationship between ethics and politics. One strong idea of the article is that the State owes its meaning to the "common good", understood as the protection of human life and dignity. Thus, political praxis should be extended to the participation of civil society, in order to avoid the weaknesses of the representative institutions and strengthen their democratic sense. More political participation of the citizens gives more ethical sense to the political action, it is all about people being responsible for their own lives.
\end{abstract}

\section{Keywords:}

Ethics / Politics / State / Ethical Sense of Politics / Democracy / Participation

\section{Introducción}

Desde los inicios de la filosofía política siempre la ética ha tenido un lugar importante, sea para enriquecer las propuestas políticas como para cuestionar el poder político. Sin duda, esta relación ha tomado formas distintas a través de los tiempos y sociedades. $Y$ nuestra época también ha hecho problemática esta relación, por lo que repensarla sigue siendo una tarea permanente. Las formas corruptas de hacer negocios, la política vista como oportunidad de enriquecimiento, los sistemas económicos ilegales que alimentan las sociedades (como el narcotráfico), las estructuras coloniales de la organización estatal, van favoreciendo una separación preocupante de la ética y la política.

La forma de mi exposición será a través de plantear cuestiones. Me interesa comenzar con las preguntas porque nos ayudan a tener una actitud exploratoria, no sistemática. El frescor de las preguntas nos hace pensar, explorar nuevos caminos 0 recorrer los antiguos con nuevas sensaciones. Asumiré que estas preguntas son las que se haría un ciudadano promedio, interesado en estos asuntos. Entonces, empecemos con las preguntas y ensayemos unas respuestas.

1 Doctor en Filosofía, docente en la Universidad de Lima y en la Universidad Nacional Mayor de San Marcos. Autor de artículos sobre ética, filosofía asiática, antropología, y de libros como Ética. Definiciones y teorías (Lima: Fondo Editorial de la Universidad de Lima, 2013). Miembro de la Sociedad Peruana de Filosofía, de la Asociación Peruana de Ética y Filosofía Política y de la Asociación Iberoamericana de Filosofía Práctica. 
Q1: Suele decirse que la ética tiene que ver con la dimensión personal, mientras la política con la dimensión pública. Si esto es así, ¿cómo entender la ética política?

Los límites entre lo personal y lo público nunca son fijos, dependerán de las creencias sociales de cada época. Si encerrásemos a la ética a la dimensión personal o privada, entonces no tendría sentido hablar de ética cívica 0 ética política o ética social. Pero si consideramos que la realidad personal está abierta a múltiples relaciones que la constituyen y le dan identidad y sentido, entonces podríamos darle su lugar a la dimensión interpersonal, con lo cual no se diluye la realidad de la persona, sino que ella constituye el soporte de la comunidad civil y esta ayuda a definir la identidad de una persona. Por eso es que puede hablarse de ética personal, ética social, ética de las instituciones y ética del sistema. Relaciones complejas, donde la emergencia de unas plantean nuevas dinámicas y problemas, pero que nunca se desprenden de la anterior. Por ejemplo, el ejercicio político de una persona (sea como congresista, ministro o alcalde) es diferente de comportarse como hijo, pero ambos están ligados en la historia personal, por lo que la formación de hijo de alguna manera influirá en la praxis política.

La diferencia entre la ética y la política no está en la cantidad de personas a las que se refiere (uno al individuo y otro a lo social), sino a las valoraciones y enfoques que se ponen en juego en cada una. Aunque también las fronteras entre ambas nunca son fijas. Sin embargo, ambas echan raíces en la acción humana y el encuentro con el otro. En ambos casos, en esta red de relaciones de cada existencia humana hay otros diferentes con los cuales debo vivir. Y desde ahí la ética y la política enfocan esas relaciones de manera diferente. Así, conceptos claves de la ética serán las virtudes, los deberes y los valores, mientras que conceptos claves de la política serán Estados, formas de gobierno, autoridad, poder, representación, etcétera. $Y$ aunque tienen sus raíces en la pluralidad y en la acción, y tienen conceptos tradicionalmente diferentes, también tienen temas comunes como la justicia, la equidad, las virtudes políticas, la guerra y la paz, entre otras. Por eso es que puede pensarse en una ética política.

Q2: Tradicionalmente se ha señalado que la finalidad de la comunidad política (y de sus instituciones) es el bien común. ¿Qué pasó con dicha finalidad?

Los pensadores, filósofos, teólogos y humanistas han considerado que la política tiene como finalidad el bien común. ¿Se vivió alguna vez así? Y aunque haya existido, ¿es posible realizarla hoy? La tradición griega, teorizada por Aristóteles, creyó firmemente que en los espacios privados no existe la felicidad, la realización humana, porque solo atienden necesidades biológicas (sobrevivir y procrear). Y por eso es que este pensador atribuyó al espacio público y — por lo tanto-al Estado la tarea de ser felices. La comunidad política, comunidad de hombres libres, tiene la tarea de hacernos seres felices. Esto era entendible en un mundo donde la comunidad política y el Estado no estaban diferenciados, pero nuestro escenario es diferente.

Las transformaciones sociales han invertido las cosas, porque ha hecho que la tarea del Estado - como entidad, organización que representa los intereses de la sociedad - no sea dar felicidad, sino gestionar las diferencias humanas para que los individuos y sus grupos encuentren y realicen sus modelos de felicidad. Así, el ámbito privado, asumiendo su función biológica, coordina con el Estado para sus logros económicos, es decir, la obtención de bienes materiales de subsistencia. $Y$ la felicidad sigue formando parte de la comunidad política, hoy llamada sociedad civil. Las personas pueden asociarse y realizar sus modelos de vida buena, lo que ellas consideran que es una vida realizada.

Y si el Estado -al separarse de la comunidad política - ya no tiene esa función humanizadora (ser feliz era, después de todo, la forma suprema de realización humana o sinónimo de vida plena), entonces, ¿para qué sirve? ¿Basta con su función administradora y coercitiva? Al parecer, no, porque desde la modernidad la existencia del Estado-nación ha sido problemática, tanto para liberales, anarquistas $y$ marxistas, a veces mirada como instrumento de clases dominantes, ente benefactor, organismo opresor y generador de injusticias, etcétera. Así, el Estado (como institución que se mira a sí misma) no tiene una función clara, porque no tiene una gran meta como el bien común, tampoco puede garantizar los derechos de los individuos ni hacerlos realmente libres. Más aún, en sociedades como las nuestras los Estados esconden muchas naciones, por lo general oprimidas por un centro de poder. La mirada institucionalizadora del Estado hace perder de vista su indesligable relación con la compleja realidad humana a la que pertenece. Es el peligro del Leviatán, de terminar contra sus creadores, posibilidad de toda instrumentalización. Replantearse el sentido del Estado no puede estar desligado del destino de los seres humanos a los cuales representa; por eso se hace necesario recuperar la relación entre las comunidades políticas y el Estado.

Pero, ¿qué es el bien común? El bien común es un concepto abstracto para referirse a un marco comprensivo que supone respuestas a cuestiones como la naturaleza humana, el destino de la comunidad política, el sentido de las instituciones, etcétera. Además, presupone una respuesta al cómo deberían vivir los sujetos en ese marco ideal. Por eso es que los contenidos de este concepto siempre serán diferentes para un religioso y para un laico, para un filósofo y un teólogo, para diferentes sujetos culturales. $Y$ como el marco comprensivo de cada quien tiende a excluir al de los demás, entonces, poco a poco, se devalúa este concepto, salvo que la sociedad sea homogénea, que no es el caso de las sociedades contemporáneas.

No quiero decir que el "bien común" haya dejado de ser importante $\mathrm{y}$, por lo tanto, deberíamos desecharlo de la reflexión ética. Lo que sugiero es que, en una época donde se valora la diversidad, sepamos construir socialmente nuestros marcos del bien común a través de acuerdos mínimos en las sociedades. Ya no puede ser invento de filósofos, políticos o teólogos, sino de grandes acuerdos sociales. Este concepto normativo puede seguir siendo valioso, pero sin pretender que a este concepto le sigue solo una forma 
de contenido específico. Sin embargo, para disipar el posible relativismo, este bien común debe estar sostenido por mínimos de moralidad que tiendan a afirmar los lazos de relaciones y de sentido entre las distintas personas y culturas. Y un mínimo fundamental es la vida humana misma. Si la comunidad política reconoce que alberga diferentes comunidades civiles, necesitará coordinar mínimos morales para la comunicación entre sujetos que piensan diferentes. De lo contrario, la imposición de una concepción del bien común fuerte implicaría atentar contra la vida y la dignidad de las demás personas.

Así, una idea de bien común en nuestros días debe tener como fundamento la vida humana y su dignidad. Desde estos presupuestos normativos, las culturas podrán seguir afirmando diferentes concepciones de lo que consideran deseable para ellos y sus comunidades.

Q3: Si la tradición dice que la tarea de la política es el bien común, ¿por qué frecuentemente hay un desprestigio de la política?

Muchas son las razones del desprestigio de la política, especialmente porque la complejidad del organismo político y la intervención de los criterios económicos hacen difícil el cumplimiento de su objetivo tradicional. A esto se suma el predominio de intereses particulares de los políticos que convierten la política en un campo más de negocios y privilegios. Pero si nos percatamos, históricamente siempre ha habido un descrédito de la política. Ya en la Apología, Sócrates tiene una imagen negativa de la política, por lo que prefiere hacer otro tipo de política, conversar con sus conciudadanos. Esta actitud contrasta con la recuperación ideal de la política que procurarán Platón y Aristóteles. Por lo menos Sócrates tiene una doble visión de la política, una la oficial, institucional, formal, otra la dialógica, la que él practicaba. Contemporáneamente, distinguimos la política desde el Estado y la política desde el ejercicio de la ciudadanía. El desprestigio de la política oficial debe confrontarse al ejercicio de la participación de los ciudadanos, por lo que sería la apuesta por un modo nuevo de hacer política, la cual apreciaba Arendt (1997). De ese modo, el logro del bien común (que, en su forma concreta, es organizar la convivencia de la pluralidad y dar soluciones a los conflictos que la pluralidad genere) ya no sería exclusivo del Estado, sino de toda la comunidad política o de la sociedad civil. Después de todo, esto es lo que subyace en el concepto de subsidiariedad, principio de una genuina democracia participativa.

Así, las actividades de las ONG, asociaciones civiles, grupos profesionales, movimientos sociales, etcétera, no deberían limitarse a reclamos o luchas por reivindicaciones, sino pensar su participación como una tarea política de ir conformando la convivencia social, que incluye tener en cuenta las múltiples voces que en ella hay, así como diseñar estrategias de solución de conflictos. En resumen, es la tarea civil, política, de ir realizando el bien común.

\section{Q4: ¿Necesitamos de una razón fuerte} para darle legitimidad a la praxis política?

Las grandes justificaciones fuertes de la política han sido dadas desde la filosofía y la religión. Por ejemplo, se ha justificado la comunidad política a partir de la naturaleza humana, por lo que existiría un orden natural o divino que los hombres deberían realizar en este mundo. Desde el darwinismo filosófico se han realizado nuevas justificaciones "naturales" o "científicas" a la praxis política (a veces también para negarla). Pero cualquiera que sea la posición de adoptemos, ¿esto producirá la única legitimidad a la praxis política? No lo creemos, principalmente porque dichas respuestas tienden a afirmar las diferencias humanas, es decir, formarían parte de las concepciones de vida buena que algunos sujetos adoptan y quieren ser trasladados al ámbito político para darle sentido a dicha praxis, lo cual puede ser justificado, pero no se justificaría que sea asumida como la única respuesta verdadera.

Algunas personas consideran que necesitamos una visión para sacar adelante este país, sea en su forma de vuelta al catolicismo o ideología nacionalista. Es decir, que las diferencias requieren de una unidad fuerte, una cosmovisión integradora, que nos una en un objetivo común. Y solo así la política podría volver a tener una verdadera vocación de servicio. Pero este discurso se anula a sí mismo, porque todo discurso requiere de otro y así esta forma de hacer política solo necesitaría de los sabios, los iluminados, pero no de los ciudadanos. Afirmo que los ciudadanos son indispensables porque de ellos depende crear un mundo compartido, ellos son responsables de hacer un mundo común, mediante el ejercicio de la palabra y la acción. Pero en una cosmovisión integradora y única ya no tiene sentido este tipo de ciudadano, sino esclavos, vasallos, sirvientes, robots, etcétera.

Quizás se diga: "¿y si la gente no quiere asumir sus propios destinos? ¿No sería mejor la figura del sabio político?" Esto sería como decir que mientras llegamos a la libertad, a la tierra prometida de la libertad, necesitamos esclavizar a las personas por su propio bien. Así, se justifican los déspotas ilustrados, con tal que dirijan a las masas al paraíso terrenal. Los déspotas ilustrados, dentro de una cultura egoísta y consumista, son muy escasos y su aparición depende de muchos factores. Pero, sobre todo, los déspotas ilustrados son todavía expresiones del ojo de Dios, es decir, de la capacidad sobrehumana que tendrían algunos individuos para saber lo que es bueno y dirigir los destinos de su patria. Considero que eso sigue siendo evadir la responsabilidad de nuestras propias existencias colectivas. La idea marxista de una "dictadura del proletariado" (obviamente dirigido por unos iluminados) tiene los mismos problemas del déspota ilustrado.

Q5: ¿Cómo llegar al poder político sin afectar la convivencia humana, la dignidad de las personas que intervienen en la confrontación política?

Si la política es vista como el campo de batalla que distingue entre amigos y enemigos, entonces la dignidad de las personas no sería un criterio suficientemente fuerte para moralizar la búsqueda del poder. Y si a esto se agrega el interés de conservar el poder, la política puede fácilmente desplazarse a ser como un juego de ajedrez, antes que entenderla como la acción 
de la palabra para el bien común. Y el ajedrecista político solo requiere astucia, habilidad para mover bien sus piezas, aunque estos sean personas. Comprar votos y conciencias será una de sus armas preferidas, para así asegurar un ejército de leales a los que pueda mover según su estrategia. Piezas que, en algún momento, puede sacrificar. Mientras, la otra forma de hacer política, desde la acción libre de la palabra, requiere encuentro con el otro, saber escuchar y decir, participar con el riesgo a equivocarse, y así construir un proyecto juntos.

El modelo ajedrecista de la política está obsesionado con el poder, es la "erótica del poder", el disfrute egocéntrico del poder hasta el punto de creer que sin él nada mejorará. Una erótica que ciega, porque ya no interesa el bienestar de la comunidad política sino solo el placer de mantenerse en el poder. Lo que supone una identificación con él, por lo que sin ese poder se perdería la identidad personal. Es como la codicia, la ambición desmedida de poseer, de dirigir, de manipular, de ser el ajedrecista y no permitir que las piezas cobren vida propia. Desde este modelo de hacer política, ¿qué dignidad puede respetarse? Ninguna.

Además, el modelo ajedrecista del obrar político asume el poder de una manera peculiar, el poder radica en el ajedrecista, no en las piezas. Mientras lo que estamos afirmando es que el poder radica en las personas, en la unión de las pluralidades, en la sociedad civil organizada y no organizada. Si identificamos solo el poder con el aparato estatal, ocultamos su real fuente: las personas. Y el poder institucionalizado termina actuando como el Leviatán, hasta desconocer su propia fuente. Superar esta creencia instalada en nuestra cultura es un reto que tiene todo ciudadano que participa en el debate público.

Q6: ¿La moralización de la política pasa por moralizar al sujeto de la política, es decir, al gobernante?

El sujeto de la política es, en primer lugar, la comunidad política en sus múltiples organizaciones civiles y movimientos sociales. Estos sujetos políticos son el sostenimiento del poder estatal, el cual el gobernante usufructúa. Por eso es tan vital para los gobiernos no perder la legitimidad, la confianza de la sociedad. Mirar la política desde los ciudadanos destruye la sobrevaloración de la imagen dominante de la autoridad política, para devolverle su sentido de servicio.

Aunque el gobernante no es el sujeto político por excelencia, hablemos del rol moral de este. Existe la creencia de que un gobernante moral sería la clave para moralizar el sistema político. Por lo tanto, deberíamos moralizar a este sujeto político que asumirá el poder. Esto puede tener dos variantes. Una que se trata de esperar que surja un líder moral, íntegro, que tome las riendas del poder y lo transforme moralmente, lo cual no deja de ser una vana ilusión, porque desconoce la realidad y dinámica de la política, que no es mero apéndice de la ética. Es como creer que una persona buena es garantía de un gobernante bueno. La otra variante, al estilo griego y confuciano, es la necesidad de educar personas que asumirán el poder. Hoy día, aunque ya existen escuelas de gobierno, todavía interesa poco si los sujetos están preparados, solo interesa si cumplen requisitos formales para participar de los asuntos públicos. Existieron pueblos que preparaban a su gente para asumir las funciones públicas, asunto escasamente importante para la mayoría de sociedades democráticas, porque se considera que atenta contra los derechos fundamentales de los sujetos, derivación que considero errónea. Quizá sea interesante que, en el futuro próximo, las funciones públicas que tienen que ver con la administración estatal solo admitan gente preparada, formada para sumir dichas responsabilidades. Así, la formación en las escuelas de gestión pública y gobierno serían condiciones necesarias para el ejercicio de la administración pública. Pudiera ser que esto permita una mayor racionalidad en la administración del Estado. Mientras se deje otro espacio para la participación más libre, como el Congreso y otras instancias. Lo cierto es que se debe replantear la necesidad de educar a los funcionarios públicos, para que sea gente de carrera. Del mismo modo, los partidos deberían formar líderes, dirigentes, "profesionales" de la política, en lugar de incluir gente solo por el grado de inversión en una campaña.

Los gobernantes siempre han sido un modelo de acción para los ciudadanos, lo contrario también ha tenido su resonancia. La figura del gobernante dictador genera pequeños dictadores en distintos sectores. Aunque sea un asunto de subjetividad colectiva asumir al gobernante como modelo, esto es un criterio a tener en cuenta en las actitudes y prácticas del político. Lo que quiere decir es que su conducta está influyendo en otros, por lo que debe tener cuidado con lo que hace. Aunque siempre debe reconocer que la fuente de su poder no está en él ni en su grupo político ni en Dios, sino en los ciudadanos.

Q7: ¿O la moralización de la política requerirá la autorregulación de la política, es decir, de las estructuras políticas a través de un marco deontológico?

Existe un marco deontológico en nuestro país, un código de ética del funcionario público (Ley № 27815, de 2002), donde se señalan principios, deberes y prohibiciones. La autorregulación, por medio deontológico, es importante, pero insuficiente cuando no va acompañada de otros aspectos institucionales, colectivos y personales. Decir que el político debe ser neutral, transparente, responsable, justo, equitativo, eficiente, etcétera, no es suficiente en una organización donde la corrupción se encuentra como parte de su estructura y cuando los sujetos tienen hábitos corruptos asumidos como "normales", por lo que autorregulación requiere, además del aspecto deontológico, trabajar el aspecto institucional (sea en sus formas de gestión o vigilancia) y educativo. Los funcionarios públicos deberían ser el ejemplo del ejercicio de la palabra en sus actividades, no asumirlas como trabajos burocráticos donde solo importa conseguir las metas individuales. Esta autorregulación funcionará en la medida de que haya claras divisiones de poderes, mayor sentido de las leyes y, sobre todo, reconocer que la fuente del poder son los ciudadanos.

Pero como no podemos esperar al gobernante ideal 0 a los funcionarios e instituciones ideales, los ciudadanos tenemos que bregar por vigilar a nues- 
tros gobernantes y sus instituciones $y$, de ese modo, ganar los espacios de participación y vigilancia civiles, por lo que nunca serán suficientes las autorregulaciones deontológicas. Deben ser sostenidas por las prácticas autorreguladoras de la propia sociedad civil (partidos, sindicatos, movimientos sociales, ONG, etcétera), de lo contrario, ¿qué legitimidad podrían tener para exigir moralización del Estado?

Q8: El realismo político ha acentuado la diferencia entre la ética y la política. ¿Cuál es el sentido de la autonomía de la política?

El reclamo moderno de autonomía de la política -asumido ya como un hecho por buena parte de los teóricos actuales-implicaba reconocer la dinámica propia de la actividad política, que no se explica plenamente desde la ética y la religión. La política moderna toma su distancia de normas morales y de mandatos religiosos, porque impedía el conocimiento de la praxis política misma. Sin embargo, si bien esta actividad toma distancia de estas otras dos actividades humanas, no puede considerarse autónoma en sentido absoluto, porque la política es parte de las acciones humanas, 0, como decía Arendt, es la acción misma. Por eso es que ella entiende la política desde las características de la acción humana. Mirada así, la política dependería de los rasgos de la acción, por lo que el intento de separarla sería convertirla en un concepto puramente abstracto y sin vida que la anime.

¿Y cómo es la acción de la que depende la política? Inspirados en Arendt (1974) tendríamos que esta acción requiere de sujetos libres, cuyo ejercicio de la palabra busca resolver problemas públicos. Y la necesidad de la acción política es la pluralidad de los hombres, que buscan vivir juntos y piensan en mínimos morales de convivencia. Pero el rasgo más llamativo de la acción humana es la capacidad de empezar algo nuevo, lo que Arendt llama "natalidad", por eso la acción humana tiene siempre algo de imprevisible e irreversible. Las iniciativas nos colocan justo en el inicio de algo, en el comenzar de nuevo. Y si la acción es la categoría política por excelencia, entonces no está circunscrita ni al
Estado ni a unos especialistas, sino a todo ciudadano que quiera asumir la responsabilidad de vivir con otros seres humanos iguales y diferentes.

Q9: ¿No existen situaciones donde la política suspende la ética? ¿0 debemos esperar que el político actúe siempre como un santo?

Dado que la política se realiza en el mundo humano marcado por lo contingente, lo inesperado, lo nuevo, entonces, no sería muy sensato decir que nunca la ética puede ser suspendida por la política. Si bien es cierto que no es deseable una política sin principios, como lo quería Gandhi, una actitud atenta a las personas no puede negar esa posibilidad. Pero, problematicemos, ¿qué significaría la suspensión política de la ética? ¿Son las posibilidades que trae la contingencia humana? ¿0 es el establecimiento de un nuevo principio? Y si existiese esa posibilidad, de suspender la ética, se haría por razones estrictamente personales (como la ambición de conservar el poder a costa de engaños y otras modalidades inmorales) 0 por razones éticas (como ir a la guerra para defender a los ciudadanos de las agresiones de tropas extranjeras). En ese caso, suspender la ética solo por razones personales no sería moralmente aceptado. Mientras que suspender la ética por defender la comunidad política podría tener mayor justificación moral. Pero este último caso requiere de unas circunstancias específicas que deben ser pensadas prudentemente por el gobernante y por ciudadanos, pues en todo acto de guerra existen víctimas inocentes. Por eso se hace necesario recurrir a instituciones mediadoras que puedan evitar el conflicto armado.

Es difícil justificar la suspensión de la ética por razones personales, por lo que debe encubrirse -engañarse sería mejor decir- con otras justificaciones que la sociedad acepte. Pero también se hace difícil justificar la suspensión de la ética por razones de ética política (como engañar a un pueblo por su bien). $Y$ es que por razones "éticas", la política también puede actuar arbitrariamente, como invadir otros pueblos para llevarlos a la "libertad" y a la "democracia". Es una línea delgada la utilización de justifica- ciones éticas (de cómo deberían vivir los ciudadanos) para actuar contra la moral (derechos fundamentales que hoy asumimos). Por eso, frente a la posible arbitrariedad de los gobernantes se hace indispensable tener en cuenta los mínimos de convivencia, a pesar de que nuestras éticas sean diferentes. Mi imagen de ser un pueblo guardián de la libertad de la humanidad (autoimagen ética) no puede llevarme a atropellar derechos fundamentales. Y si lo hago, saber - a partir de esos mínimos - que lo realizado está mal, que es reprobado por los demás.

\section{Q10: Y ¿cuál es la tarea de la ética en la política?}

La crítica, la problematización, seguir siendo el tábano cívico que pica el trasero de la institucionalidad burocrática y su ejercicio "racional" del poder, sobre todo cuando la historia ha mostrado que las injusticias también provienen del Estado. La ética en la política no sueña en convertir en ángeles a los seres humanos, el angelismo puede conducir a posturas principistas y dogmáticas que rayan con actitudes violentas. Tampoco debe conducirnos al cinismo, que al ver la historia de los hombres y sus instituciones haga perder el sentido y valor de la ética. Un sano realismo que asuma las dimensiones de esperanza y utópica que tiene la ética, nos podría prevenir el angelicalismo y el cinismo. 0 como quiere Edgar Morin (2004), asumir las contradicciones ético-políticas, como son lo urgente frente a lo esencial, la necesidad de combinar la audacia y la precaución, asumir las contradicciones de la tolerancia, las contradicciones posibles entre el bien colectivo y el bien individual, los conflictos entre la comprensión y el combate político, por lo que sugiere luchar sobre los dos frentes. Así, no existe una regla para resolver estas contradicciones, salvo la prudencia, virtud ética y política por excelencia. Pero una prudencia que afirme la política como relación entre seres humanos iguales y diferentes, rechazando la visión de instrumentalizar o cosificar a las personas para usarlas según distintos intereses.

Aranguren (1968) veía que la ética en la política está caracterizada por su problematicidad, que puede mante- 
nernos entre el optimismo idealista y el pesimismo realista. Pero una problematicidad defensora de la dignidad humana, atenta a las experiencias de desprecio y humillación que sienten las personas. Quizá eso permitiría dejar que los discursos políticos sean abstractos (sociedad libre, libertad, comunismo, reino de los fines, crecimiento económico, igualdad, inclusión social, etcétera) y que estén dispuestos a escuchar a las personas que sienten la injusticia y la humillación en sus vidas. Así, podríamos tener una política más humana, más ética. Un Estado ético, en lugar de estar centrado en intereses egoístas. La defensa de la comunidad política por parte del Estado es la defensa de la vida de los ciudadanos, de todos y cada uno de ellos. La razón de ser de esta institución política es la vida de sus integrantes, por lo que pierde legitimidad cuando se desentiende de las necesidades vitales 0 mata a sus opositores.

Q11: Finalmente, ¿hay un aspecto ético distintivo en la política?

El carácter radicalmente ético de la política es la participación de los ciudadanos, en vistas de la afirmación de la vida. Y mientras se abran más espacios de participación de los ciudadanos - sea para propuestas, expresión de intereses, vigilar a sus representantes y a los funcionarios públicos, señalar las directrices del Estado, etcétera-, más nexos estableceremos entre libertad y responsabilidad, necesarias para el desarrollo de la vida humana. Hacerse responsable de la comunidad y la sociedad en la que se vive debiera ser el rostro ético de la democracia. No es solo el Estado de derecho ni la existencia de partidos que representen a las personas, sino la misma participación de ellas, que no es sino responsabilizarse de sus propias vidas y destinos. Las comunidades campesinas de la sierra sur del Perú son un ejemplo de esa práctica política: los campesinos se reúnen y discuten sobre sus asuntos comunales.

El modelo de la democracia representativa está en crisis. Y lo está porque se sustenta en la competencia, en la lucha entre individuos egoístas o que tienen que ser egoístas para ganar. El sistema representativo basado en la competen- cia hace surgir en los individuos sus demonios que terminan dañando a los otros. La decadencia de la democracia basada en partidos 0 alianzas se muestra en lo siguiente:

Objetivamente, los gobernantes que no cumplen su promesa; los grupos tienen que hacer alianzas con otros con ideologías e intereses diversos, pero unidos solo porque hay otro enemigo común; las inversiones que vienen de empresas y gente de dinero, teniendo en cuenta que no se invierte para perder sino para ganar y recuperar su dinero, a través de negocios futuros; el monopolio del poder por parte de los grupos ganadores, lo que convierte a los demás (competidores y electores) en simples espectadores, de sus desaciertos e inmoralidades; negocios turbios que van desde el pago de un porcentaje de las empresas que quieren hacer negocios con el Estado hasta la entrega descarada de paquetes de dinero a los políticos para obtener algún favor (Ios vladivideos han sido un ejemplo del extremo a lo que pueden llegar la corrupción política); amenazas o perjuicio físico a los oponentes, no solo en procesos electorales sino mientras se asume el poder; formación de malos hábitos, especialmente con respecto al uso del dinero público (gastos indebidos de caja chica, empleados fantasmas, pago de cupos por ingreso a trabajar al Estado, estado de cuentas arregladas, etcétera); pérdida del sentido del bien común, de la finalidad del cargo público, concentrándose en la administración o en aprovechar los momentos para obtener algún beneficio personal; pugna por tener poder en algún espacio del Estado, copar esos espacios se vuelve una tarea política, obviamente para obtener un provecho posterior; la política como espectáculo, donde unos buscan tener más ratings, salir más en pantalla, ganarse a la prensa, quedar bien con el público; representantes que se venden a intereses económicos y políticos; políticos empresarios que utilizan las instituciones públicas para beneficio privado, etcétera. La lista puede seguir. $Y$ todo tiene que ver, en mayor o menor medida, con la corrupción política. En cada país toma rostros y formas distintas, pero en todos ellos la política representativa está trayendo más problemas que soluciones.

Subjetiva e intersubjetivamente, tomar decisiones solo por cálculo costo -beneficio, tanto en alianzas como en el otorgamiento de beneficios a terceros. El dicho popular, "a mis amigos todo, a mis enemigos la ley", pasa a ser norma del gobernante. Para obtener y mantener el poder se recurre a ofensas, difamaciones, atentados contra la dignidad de las personas, a fin de crear una imagen negativa y descalificar moralmente al adversario; actitudes egoístas, soberbias e intolerantes, frutos de haber ganado en la competencia política, y ante cualquier propuesta bien dirían: "me han elegido a mí, no a usted". La hipocresía, la doble moral, que muestra a un gobernante o político en general amable, "buena gente", pero que puede estar dispuesto a cometer los actos más condenables moralmente. La corrupción de la palabra, que va desde el populismo hasta las palabras soeces, expresiones de las que Habermas llamaría una comunicación estratégica. Por lo tanto, el poder no escucha, hasta que la población hace sentir su malestar con protestas. "Amiguismos", "camarillas", grupos mafiosos en diferentes niveles del poder. Y la lista puede seguir también acá.

Si esto está en crisis y no podrá ser resuelto por más leyes ni llamadas a la conciencia contra la corrupción, tenemos que repensar la praxis política. No veo otra alternativa que radicalizando la política, lo que significa devolverle su sentido ético, que no es otra cosa que hacer que los ciudadanos participen y sean responsables por sus propias vidas. La antropoética que sostiene esto es que somos seres interdependientes y contingentes, por lo que hay otros con los que debo hacer un destino común, otros que son iguales y deferentes (como decía Arendt), otros que tienen dignidad y derecho a escuchar y ser escuchado. Y nuestra actitud más coherente con esto es la del cuidado, la de cultivar una actitud de atención al mundo. Atención cuidadosa ante las formas de olvido, explotación, discriminación, injusticias y tener la disposición de aprender de las diferencias. 
Las competencias egoístas alimentan la competencia en el mercado, la misma política se ha vuelto una expresión suya. Y desde este presupuesto ningún problema político puede resolverse, todo lo contrario, se agrava. La política como competencia es decadente, primero porque olvida a los ciudadanos y los mira de lejos, como vasallos; segundo, porque se convierte en campo de batalla, donde el poder político termina aliándose con el poder económico, frente a los intereses de personas y comunidades menos favorecidas. Así, el encuentro de los ciudadanos, la expresión de sus intereses, la participación en los asuntos de su comunidad, quedan relegadas, más aún, asumidas por el "papá" Estado. Los liberales se quejan del Estado paternalista, pero hacen poco para darle poder a los ciudadanos, creyendo que basta con que tengan dinero en el bolsillo para que arreglen sus problemas en el mercado.

Tomemos la sugerente idea de Nancy Fraser (2006) de "paridad participativa" como ideal normativo de la actividad política. Las sociedades como la peruana tienen muchas carencias, necesidades que, al no ser atendidas, hacen que los sujetos se sientan humillados, pudiendo generar además sentimientos que impulsen a actuar, a hacer algo contra esa condición. Son las reivindicaciones sociales expresiones suyas. La paridad participativa busca afirmar la necesidad de un espacio público abierto a las diferencias, espacio de debate público, que permita deliberar sobre las necesidades y bienes sociales fundamentales, y la manera de conseguirlos. Obviamente no será un espacio homogéneo, sino heterogéneo, porque los seres humanos somos afectados por muchos condicionamientos. Pero esa deliberación pública podría ser el ejercicio de la responsabilidad como ciudadano, disminuyendo las arbitrariedades de los poderes políticos y económicos, muchas veces producto de ambiciones desmedidas.

Hasta ahora nos conformamos con que los medios masivos formen la opinión pública, pero sabemos que ellos mismos son expresiones de intereses. ¿Podremos hacer que sean realmente medios donde se exprese el debate público? ¿Qué sean realmente medios de las necesidades e intereses de las personas, especialmente cuando están fuera del centro del poder estatal y económico? Eso requeriría una mirada y escucha atentas de parte de los comunicadores a las personas en sus distintas condiciones. Hay millones de historias colectivas y personales que pueden ser rescatadas, para darnos cuenta de que existe razón para la esperanza de un país mejor. Así, una democracia participativa tendrá que replantear el sentido de los medios.

Los analistas políticos se quejan de que nuestra democracia no tiene partidos; además, critican al Estado por su papel paternalista y burocrático, y algunos ven los nexos entre corrupción política poder económico. Pero son muy pocos los que quieren darle más poder a las personas para que asuman sus propios destinos. Esta democracia representativa ha creado súbditos, necesitamos pensar en formas de participación para que los ciudadanos sean dueños de sus propias vidas. La participación pública, guiada por el ideal de "paridad participativa", podrá ir redefiniendo el rol de los partidos y alianzas políticas, el sentido de las organizaciones civiles, el papel del Estado, etcétera, ¿estaremos dispuestos a dar ese salto ético en la política?

\section{Bibliografía}

Aranguren, J. L. (1968). Ética y política. Madrid: Guadarrama.

AREndT, H. (1974). La condición humana. Barcelona: Seix Barral.

Arendt, H. (1997). ¿Qué es la política? Barcelona: Paidós.

Fraser, N., Y Honneth, A. (2006). ¿Redistribución o reconocimiento? Un debate político-filosófico. Madrid: Morata.

Morin, E. (2004). La Méthode 6. Éthique. Paris: Éditions du Seuil.

Polo, M. (2014). “Ética y política. Hitos históricos de una relación”, en Cuadernos de Ética y Filosofía Política, Revista de la Asociación Peruana de Ética y Filosofía Política (Lima), año 3, núm 3. 